\title{
Determination of Folic Acid in Food by Differential Pulse Voltammetry with ZnO@GO Nanocomposites Modified Glassy Carbon Electrode
}

\author{
Jing xi Ma ${ }^{1}$, Liu Yang ${ }^{1}$, Lei Wang ${ }^{2}$, Shu Qing Wu ${ }^{l^{*}}$, Yan Liu $^{3 *}$ \\ ${ }^{1}$ School of Food Science and Engineering, Changchun University, Chang'Chun 130012, China \\ ${ }^{2}$ Cereal School Jilin Business and Technology College, Chang'Chun 130507, China \\ ${ }^{3}$ College of Life Sciences, Changchun Sci-Tech University ,Chang Chun 130000, China \\ *E-mail: wushuqing041128@sina.com and ly78210310@sina.com
}

doi: $10.20964 / 2021.01 .04$

Received: 1 September 2020 / Accepted: 9 October 2020 / Published: 30 November 2020

The ZnO@GO nanocomposites/GCE for electrochemical determination of folic acid was conducted in this study. $\mathrm{ZnO}$ nanoparticles were synthesized by the sol-gel and homogeneously mixed with graphene oxide in a weight ratio of $0: 1,1: 0,1: 2,1: 1$ and 2:1 and applied for modification of the GCE surface. FESEM and XRD analyses were applied for structural studies and cyclic voltammetry and differential pulse voltammetry techniques were conducted for electrochemical studies of folic acid sensors. Results showed that high porous surface $\mathrm{ZnO} @ \mathrm{GO}$ nanocomposite included the zinc oxide nanoparticles which homogeneously anchoring on mesoporous graphene oxide and acts as a stabilizer between the graphene oxides sheets to prevent sheet aggregation. Results of electrochemical studies showed that ZnO@GO nanocomposites with a weight ratio of 1:1 demonstrated high stability, high sensitivity and the facility in charge transfer for determination of folic acid. Results also showed that the wide linear range, high sensitivity and low limit of detection were obtained 1 to $400 \mu \mathrm{M}, 0.0637$ $\mu \mathrm{A} / \mu \mathrm{M}$ and $0.04 \mu \mathrm{M}$ for folic acid determination, respectively. Comparison of electrochemical activity ZnO-based sensors demonstrate that the prepared ZnO@GO nanocomposites/GCE illustrated better or superior linear range and sensitivity for determination of folic acid. Analytical applicability of the ZnO@GO nanocomposites/GCE to determine folic acid in apple juice indicated that the prepared electrode was the reliable folic acid sensor in food samples due to acceptable vale of recovery (more than $94.60 \%$ ) and RSD (less than $4.25 \%$ ).

Keywords: Folic acid detection; Differential pulse voltammetry; Analytical applicability; Apple juice; Sensitivity

\section{$\underline{\text { FULL TEXT }}$}


(C) 2021 The Authors. Published by ESG (www.electrochemsci.org). This article is an open access article distributed under the terms and conditions of the Creative Commons Attribution license (http://creativecommons.org/licenses/by/4.0/). 